\title{
EM BUSCA DE UM MODELO DE ACESSIBILIDADE AUDIOVISUAL PARA CEGOS NO BRASIL: UM PROJETO PILOTO
}

\author{
Eliana Paes Cardoso Franco*
}

RESUMO: Apesar da Lei no. 10.098/2000 tcr assegurado aos portadores de deficiência auditiva e visual o livre acesso aos meios de comunicação, foi apenas em 2004 que o Decreto no. $\mathbf{5 . 2 9 6}$ determinou a implantaçāo de très sistemas que garantem o amplo acesso desses cidadāos ao audiovisual. Contudo, só em março de 2006, após mais duas modificaçöes, este decreto começou a ser amplamente discutido. A questão da acessibilidade audiovisual não ć simples para um pais em desenvolvimento, porque implica alto investimento em tecnologia e cm recursos humanos. Em se tratando deste último, vale perguntar como a formação de profissionais em acessibilidade audiovisual se dară. Este artigo revela o esforço pioneiro de um grupo de pesquisa em tradução audiovisual da Universidade Federal da Bahia para introduzir a questão da acessibilidade na universidade, especialmente no que se refere aos cegos e deficientes visuais. $O$ artigo relata os resultados da primeira fase de um projeto piloto (etapa Salvador), o qual busca elaborar um modelo de audiodescriçāo que vá de encontro às necessidades e preferências do público deficiente visual brasileiro.

UNITERMOS: tradução audiovisual; audiodescrição; acessibilidade; cegos; deficientes visuais.

ABSTRACT: Despite the fact that the Law Project no. 10.098/ 2000 ensured to the hard of hearing and visually impaired

* Universidade Federal da Bahia. 
the free access to all means of communication, it was only in 2004 that the Decree no. 5.296 determined the implementation of three systems that guaranteed the ample access of these citizens to the audiovisual medium. However, it was only in March of 2006, after two modifications, that this decree started to be amply discussed. The issue of accessibility is not a simple one for a developing country, because it implies large investments in technology and human resources. As regards the latter, it is worth asking how the training of professionals in audiovisual accessibility will happen. This article reveals the pioneering effort of a research group in audiovisual translation of the Federal University of Bahia to introduce the issue of accessibility in the academy, especially as far as the blind and visually impaired are concemed. The article reports on the results of the first phase of a pilot project (phase Salvador), which aims at elaborating an audiodescription model that can meet the needs and preferences of the Brazilian visually impaired audience.

KEYWORDS: audiovisual translation; audiodescription; accessibility; blind; visually impaired.

\section{Introdução}

Atualmente, a populaçāo brasileira atinge por volta de 180 milhões de pessoas. No ano 2000, o Instituto Brasileiro de Geografia e Estatîstica (IBGE) contou 2.4 milhões de pessoas com deficiência audiovisual, dentre elas, 148 mil cegos, divididos entre 77.900 mulheres e 70.100 homens. A maioria dessas pessoas cegas concentrava-se nas regiōes nordeste $(57.400)$ e sudeste (54.600). Nos seus principais estados, Bahia e São Paulo, também se concentravam o maior número de pessoas cegas, 15.400 e 23.900, respectivamente.

No ano de 2004, a Organizaçāo Mundial de Saúde ${ }^{1}$ estimou que havia cinco milhōes de pessoas cegas no pais, um au-

1 Publicado pela Revista O Globo, Rio de Janeiro, 15 de agosto de 2004.

TradTerm, 13, 2007, p. 171-185 
mento incrivel se comparado ao ano 2000. Em março do mesmo ano, o canal de televisào TV Câmara informou que já havia 25 milhōes de pessoas cegas ou deficientes visuais no pais. Mesmo assim, a indústria audiovisual ignorou o problema, e perdeu a oportunidade de aumentar seus indices de audiência. Nem o polèmico projeto da Ancinav (Agência Nacional do Cinema e Audiovisual), que prega a acessibilidade, conseguiu perceber a importāncia da inclusão de deficientes auditivos e visuais como forte argumento a seu próprio favor ${ }^{2}$.

No pais da telenovela, o que provou ser mais eficiente em termos de conscientização pública para a questão dos cegos foi a global América, que invadiu a prime time dos lares brasileiros em 2005. A novela suscitou o boom dos cegos, que proliferaram nos programas de televisāo como E.Ts. que chegaram à Terra pela primeira vez. Pieguices à parte, a novela sem dúvida cumpriu seu papel social, chamando a atenção para uma causa que jả mobiliza a sociedade européia e a norte-americana por algum tempo.

É fato que, há quase seis anos, criou-se a Lei no. 10.098/ 2000 , que assegura aos portadores de deficiência auditiva e visual o livre acesso aos meios de comunicaçāo. Mas foi somente em 2004, com o Decreto no. 5.296, que a implantaçāo de três sistemas que garantem o amplo acesso desses cidadāos ao audiovisual foi determinada. Coincidência ou não, apenas depois do alvoroço causado pela novela que esse decreto, e sua Norma Complementar, começaram a ser discutidos, em março de 2006. O projeto “Acessibilidade em comunicação na televisāon (NBR 15290), lançado pela ABNT em outubro de 2005 e válido a partir de novembro do mesmo ano ${ }^{3}$, foi um dos documentos que discutiu a referida norma em consulta pública na Esplanada dos Ministérios (26/03/2006). De acordo com o projeto, a norma da acessibilidade visa, principalmente a:

a) viabilizar à maior quantidade possivel de pessoas, independentemente de idade, limitação de percepçāo ou

2 Veja mais sobre o tema em Franco, 2006.

3 Esse projeto encontra-se disponivel on-line no sitio da ABNT. 
cogniçāo, o acesso à programaçāo televisiva;

b) dar acesso à informação e ao entretenimento proporcionados pela TV a pessoas com deficiência auditiva, visual ou cognitiva;

c) facilitar a surdos, estrangeiros residentes no pais e pessoas semi-analfabetas a aquisiçāo da lingua portuguesa escrita;

d) possibilitar o exercício da cidadania aos usuários da Lingua Brasileira de Sinais (LIBRAS);

e) permitir a pessoas que cegas ou com baixa visão o acesso às mensagens transmitidas de forma essencialmente visual;

f) permitir a pessoas que não possam ler as legendas abertas (de tradução) o acesso à programação transmitida em língua estrangeira;

g) possibilitar o acesso à informação em áreas de uso público ou coletivo com alto nivel de ruido (bares, aeroportos, saguão de hotéis etc.);

h) desenvolver a comunicação, assegurando os direitos do cidadāo estabelecidos pela Constituição Federal. (ABNT NBR 15290: 2005: p. 1)

No item 6 do projeto - "Diretrizes para o áudio com a descriçāo de imagens e sons" (p. 8) - encontramos uma narrativa tímida sobre os principios da audiodescrição, que viabilizará a acessibilidade dos cidadãos cegos e deficientes visuais ao meio televisivo. Em outros documentos elaborados em resposta ao Decreto no. 5.296/2004 - que determina a implantaçāo de três sistemas que garantem o acesso ao audiovisual por portadores de deficiência auditiva e visual - e discutidos na referida consulta pública, observamos dois pontos mencionados por todos eles:

4 Outros documentos consultados foram de autoria da Associaçāo Brasileira de Emissoras de Rádio e Televisão (ABERT), da Associação Brasileira dos Radiodifusores (ABRA), da Gazeta do Espirito Santo Rádio e TV Ltda, e da Empresa Brasileira de Comunicaçāo S/A (RADIOBRÀS). Esses documentos estāo disponiveis on-line no sitc: www.mj.gov.br/ sedh/ct/corde/dpdh/corde/resultado_consulta_publica.asp. 
a atualização tecnológica e a formação de recursos humanos. Todos os documentos concordam que a televisão digital tornará o sonho da acessibilidade mais possivel. Porém, em nenhum documento encontramos resposta efetiva sobre quem realizará e como a audiodescriçāo serả realizada.

Sabemos que cursos em traduçāo audiovisual sāo ministrados geralmente como oficinas curtas de especialização, ou como módulos de cursos de traduçāo geral, focalizando principalmente a dublagem e a legendagem, os dois modos de traduçào audiovisual mais populares no Brasil. E, se a legenda fechada, disponibilizada numa limitada programação da televisão aberta brasileira, ainda permanece um modo a ser estudado e aprimorado $^{5}$, a audiodescriçāo fica no âmbito do sonho ainda por se concretizar. E é nesse sonho que um grupo de pesquisa, formado por professores e alunos da Graduação e da Pós-Graduaçāo da Universidade Federal da Bahia e dois especialistas da Universidade Estadual de Feira de Santana ${ }^{6}$, quer investir. Ou seja, na possibilidade de tornar o meio audiovisual acessivel ao cego e deficiente visual.

Esse artigo relata os primeiros resultados deste grupo de pesquisa ${ }^{7}$, que se referem a um estudo de recepçāo da audiodescrição de um curta-metragem por cegos e deficientes visuais da cidade de Salvador, no estado da Bahia. A idéia do trabalho é aplicar o mesmo estudo em várias capitais brasileiras, a fim de que um modelo de audiodescriçāo possa ser elaborado de acordo com as preferências e necessidades de seu público-alvo, o cidadão cego/deficiente visual brasileiro.

5 Para mais informaçōes sobre a legenda fechada no Brasil, veja Franco \& Santiago Araújo, 2003.

-Vale acrescentar que essa foi a formaçāo inicial do grupo, o qual hoje é formado pelas pesquisadoras Eliana P. C. Franco (UFBa); Sandra Regina de Farias (UEFS); Iris Fortunato (UFBa) e Manoela da Silva (UFBa).

- Parte desta pesquisa foi apresentada na conferència internacional Media for All, promovida pela Universidade Autônoma de Barcelona, em junho de 2005, e os resultados finais da etapa Salvador foram apresentados na conferência MUTRA - Audiovisual Translation Scenarios, realizada pela Universidade de Copenhague, em maio de 2006. 


\section{O cego / deficiente visual na cidade de Salvador}

Existem instituiçōes e associaçōes de cegos por todo o pais. No Rio de Janeiro, uma das mais importantes é o Instituto Benjamin Constant. Nos estados de São Paulo e Bahia, encontramos cinco instituiçōes principais para os cegos e deficientes visuais: Associação Brasileira de Assistência ao Deficiente Visual - Laramara e Fundação Dorina Nowill, ambas em São Paulo, e Centro de Apoio Pedagógico ao Deficiente Visual (CAP), Associação Baiana de Cegos ( $A B C$ ) e Instituto de Cegos da Bahia (ICB), no estado da Bahia.

Para a etapa Salvador, as três instituições mencionadas foram visitadas em maio de 2005, e entrevistas foram conduzidas com pessoas selecionadas pelas instituiçōes, e que ocupam uma posição importante ou de destaque, tais como o diretor do CAP, um dos mais antigos membros cegos e assistente do presidente da $\mathrm{ABC}$, e a assistente social do $\mathrm{ICB}^{8}$ Os cegos e deficientes visuais que chegam a essas instituiçōes são, geralmente, enviados por médicos que sabem que os cidadãos encontrarāo apoio profissional nas instituiçōes. O CAP é subsidiado pelo estado, o ICB é uma instituição privada que também recebe apoio financeiro do estado, e ambas recebem doações de diferentes setores da sociedade. Por causa do apoio estatal, as duas instituiçōes seguem o estatuto do Ministério da Educação e Cultura (MEC), e profissionais que trabalham lá são geralmente empregados do estado especializados no ensino de pessoas com deficiēncia de todos os tipos. Já a $A B C$ nāo recebe subsidio do estado; contudo, todos os cursos oferecidos a seus membros são financiados pela Secretaria do Trabalho em Salvador, e todo o material usado é geralmente doado pela prefeitura. Além disso, alguns membros treinados em telemarketing frequentemente acabam trabalhando para a instituição, tentando conseguir doaçōes, dos diferentes setores da sociedade.

Devido ao apoio estatal, CAP e ICB oferecem um número limitado de vagas todo ano, e os cidadāos têm que esperar para

\& A partir de agora, serão usados os acrônimos CAP, ABC e ICB para as três instituições envolvidas. 
se tornarem membros apesar da aclamada politica das instituições de aceitar todas as pessoas. A ABC, por sua vez, é o sindicato dos cegos em Salvador, uma instituiçāo filantrópica, a qual qualquer pessoa pode se filiar, a qualquer hora, o que explica seu maior número de membros. De acordo com as entrevistas, foi descoberto, em primeiro lugar, que apenas 896 pessoas eram assistidas pelas instituições, sendo que o CAP assistia a 219 delas, entre cegas congênitas ou que adquiriram a cegueira; a $\mathrm{ABC}$ assistia a 464 pessoas, com 327 cegos congênitos ou com cegueira adquirida, e o ICB assistia a 350 pessoas, entre $70 \%$ de cegos e $30 \%$ de deficientes visuais. Se considerarmos que a cidade de Salvador é a terceira do pais, com uma população por volta de 3.5 milhōes, podemos supor que o número de cegos/ deficientes visuais é bem maior do que o registrado, o que nos leva a concluir que o número de pessoas assistidas pelas instituiçōes parece bem baixo.

Em se tratando do perfil desses cidadãos cegos e deficientes visuais, foi descoberto que o CAP atende a meninos e meninas a partir dos seis anos de idade, e adultos com nivel educacional baixo, que estāo desempregados e, portanto, dependentes de benefício governamental. Já a $A B C$ atende a apenas adultos, homens e mulheres, com nivel educacional médio, mas que estão em sua maioria desempregados. O ICB, por sua vez, atende geralmente a pessoas do sexo masculino, do zero aos dezoito anos, com niveis educacionais variados, e que estudam, principalmente.

Apesar de que a idade pode variar de uma instituição para outra, e de que o nivel educacional está estritamente relacionado à idade, um fato comum a todas as instituições é que homens e mulheres raramente exercem uma atividade profissional. No ICB, isso é esperado devido à idade e nivel educacional de seus membros. No CAP e na $\mathrm{ABC}$, muitos adultos, inclusive jovens adultos, se dizem "aposentados", no sentido de que eles fazem uso do seu direito de receber o beneficio governamental destinado a deficientes. Mesmo assim, dentre as instituiçōes visitadas, a $\mathrm{ABC}$ pareceu ser a única a desenvolver habilidades profissionais dos cegos e deficientes visuais através do ensino de técnicas de massagem, culinária, telemarketing, artesanato, cursos 
de linguas, e outros. Em se tratando do CAP e do ICB, seu enfoque é a alfabetização, ou o ensino da leitura em Braille, da escrita, e da técnica chamada "sorobã", usada para cálculos matemáticos. Por outro lado, todas as instituiçōes oferecem assistència pedagógica, psicológica e médica, alêm de uma série de atividades culturais e recreacionais.

As atividades culturais e recreacionais no CAP compōemse de uma audioteca, onde os cegos "ouvem" livros, de aulas de canto, dança e de artes marciais. A instituiçāo também promove competições de xadrez e sessões de filmes de TV. Como já mencionado, a $\mathrm{ABC}$ oferece variados cursos que objetivam inserir seus membros no mercado de trabalho. Atividades de entretenimento incluem competições de dominó e futebol, além de sessōes de filmes. No ICB sāo oferecidas oficinas de música, atividades esportivas, e visitas esporádicas a parques, ao cinema e ao teatro. Além disso, as duas últimas instituições dispõem de uma biblioteca Braille.

Como observado, cegos e deficientes visuais do CAP e da ABC estão acostumados a assistir a filmes de TV. No ICB, contudo, eles raramente o fazem, e visitas ao cinema e ao teatro sāo esporádicas por causa do custo envolvido em tais atividades, como afirmou a entrevistada. Sessōes de filmes com audiodescriçāo nunca foram vivenciadas pelos membros dessas instituiçōes, embora o CAP costumasse promover sessōes de filmes nacionais narradas ao vivo por um voluntário da instituição ${ }^{9}$. ABC e ICB, por sua vez, nunca exibiram sessões de filmes com o apoio da narração de imagens ao vivo. No entanto, a ABC mostrou um enorme interesse em promover tais sessōes, enquanto que a assistente social do ICB mostrou-se sem o menor interesse em promover tais sessões, fossem elas com narraçāo ao vivo ou com audiodescrição. $O$ mais interessante, porém, foi a justificativa apresentada pela entrevistada, que alegou que a audiodescriçāo nāo é necessária porque hả o áudio original e os cegos não tèm problema para entendê-lo.

- Tal voluntário que trabalha para o CAP é um dos membros do grupo de pesquisa que conduz o atual projeto piloto, Sandra Regina de Farias.

TradTerm, 13, 2007, p. 171-185 
As palavras da entrevistada refletem claramente uma posição que prevalece em todo o país, que é a do total desconhecimento sobre a atividade da audiodescrição, e de seu beneficio para cegos e deficientes visuais ao assistirem televisāo ou irem ao cinema. O estudo descrito abaixo revela o quão equivocada essa postura ê, e como a audiodescriçāo pode otimizar o entendimento de um filme, por exemplo.

\section{Etapas do teste de recepção}

\subsection{A seleção dos participantes}

Após a entrevista descrita acima, onde o perfil dos membros das instituições de cegos foi delineado, foi o momento de entrar em contato com os próprios membros das associaçōes a fim de explicar os objetivos da pesquisa e despertar o interesse de participação nos mesmos. Ao todo, conseguimos 13 voluntários, que acabaram se tornando dez no dia do experimento por motivos alheios à pesquisa ${ }^{10}$. Esses dez voluntários se dividiam em seis homens e quatro mulhere ${ }^{11}$, sendo que apenas um era cego congènito, três tinham baixa visão, e seis haviam adquirido a cegueira há mais de vinte anos. Suas idades variavam de 20 a mais de 55 anos. Apenas um deles tinha o terceiro grau completo, enquanto que os outros geralmente tinham o ensino médio incompleto. Apenas dois deles trabalhavam. Exceto por um par-

10 Numa pesquisa com deficientes de qualquer ordem, alguns imprevistos sāo sempre comuns. Uma chuva torrencial no dia e horảrio do experimento dificultou a mobilidade dos cegos, que ou não puderam chegar à instituiçāo a tempo, ou chegaram atrasados, ficando a clivisào de grupos desigual.

11 O grupo é imensamente grato à Associação Baiana de Cegos, por sua disponibilidade em colaborar com a pesquisa, bem com aos cidadãos que se disponibilizaram a participar do teste de recepçào da audiodescriçāo: Rosalina de Oliveira, Indiara de Carvalho Moreira, Climėrio do Carmo Pena, Jamilton Moreira dos Santos, José Márcio Soares Nunes, Gerusa Maria Ferreira de Souza, Joselita dos Santos, Jorge Luis de Lima, Alfredo Florentino Filho e Fcrnando Conceiçāo Abade. 
ticipante, nove tinham o hábito de assistir televisão, sendo seus programas, em ordem de preferência: noticiários, novelas, futebol, programas de auditório (Faustão), Fantástico, programas infantis (Sítio do Pica-pau Amarelo), e seriados da Rede Globo (ex. A grande Familia). ${ }^{12}$ Dentre os dez voluntários, cinco preferem o rádio à televisão, e quatro deles jamais tiverạm alguém que lhes descrevesse a informação visual de um filme ou programa.

\subsection{A seleção do filme}

Para uma pesquisa de apreciação da audiodescriçāo, a melhor opçāo foi selecionar um filme de curta-metragem, por apresentar uma história fechada, com começo, meio e fim. O filme Pênalti, de Adler Kibe Paz, uma produçāo soteropolitana, continha vários ingredientes favoráveis à pesquisa: duraçāo de apenas 8 minutos, filmado em Salvador, falado no mais puro "baianês", tema sobre futebol, uma pitada de sexo, e o mais importante: imagens extremamente significativas para a compreensāo do enredo.

Pênalti conta a história de Jorge, que só pensa em como participar do baba (pelada, no "paulistanês") de domingo, e se livrar do plano de sua esposa Isabel, que espera passar um dia com o marido numa excursão para a praia de Arembepe. Jorge entāo deixa o chuveiro ligado, para dar a impressāo que estava tomando banho, e foge para o campo. Isabel bate na porta do banheiro, sem a resposta de Jorge. Na cena do jogo, nenhum comentário é oferecido ao espectador, apenas um minuto de música até que Jorge sofre uma falta e marca o pênalti, que é

12 Vale notar que, de modo geral, a televisào paga jamais seria uma boa alternativa para os cegos, uma vez que muitos de seus canais exibem a versāo original em lingua estrangeira com legendas em português. Isso significa que, antes mesmo da audiodescrição, as legendas teriam que ser transformadas em texto audivel, seja pela dublagem ou pelo voiceover. Portanto, a gama de programas audiovisuais é extremamente restrita para os cegos e deficientes visuais.

TradTerm, 13, 2007, p. 171-185 
defendido pelo goleiro. Irritado, ele sai aos brados para a casa de seu amigo Antônio, para quem quer devolver a camisa do time emprestada. Ao chegar à casa do amigo, entra devagar e escuta alguns sussurros que vêm do quarto. Quando abre a porta do mesmo, dá de cara com Isabel sentada de costas, na cama com Antônio. Ela se vira, percebe o flagra de Jorge, que sai correndo desesperado pela rua. Até aqui, as cenas são regularmente cortadas por uma imagem de Jorge no alto de um barranco chorando, com seu corpo num tom de azul. Na cena final, Jorge e um homem mais velho se encontram no alto do mesmo barranco, seus corpos também em azul. O homem tenta consolar Jorge, e o convida para jogar em seu time, cujos jogadores são Garrincha, Dener, e mais outros nomes de jogadores que já faleceram. Percebe-se ai que a cor azul indica que agora Jorge é um espirito, que ele se jogou do barranco por desespero. Na cena final, Jorge e o homem vāo caminhando enquanto Isabel chega correndo, no mesmo alto do barranco, onde encontra a camisa de Antônio deixada por Jorge jogada no chão. Isabel chora.

\subsection{O processo da audiodescrição}

O processo da audiodescrição foi baseado no conhecimento adquirido em duas oficinas na Europa com dois dos maiores nomes na área, o alemāo Bernd Benecke e o inglês James O'Hara. Tendo a palavra "simplicidade" como guia, escrevemos primeiramente um rascunho do roteiro visual, tentando aplicar as três regras básicas da audiodescriçăo: nāo resumir, não interpretar e nāo antecipar as imagens. Após a primeira tentativa, revisamos o roteiro da audiodescrição em função do espaço de tempo entre diâlogos, onde o texto seria gravado.

O processo de gravaçāo representava o maior obstáculo, primeiramente porque tínhamos de pagar um estúdio, e segundo porque não tinhamos a menor experiēncia na leitura dramática da audiodescriçāo, dentro do timing imposto pelo filme. Vista desta forma, a audiodescrição parece um pouco com o processo da dublagem, mas com uma funçāo diferente. Ou seja, enquanto a primeira é informativa e gravada nos momentos de silêncio dos personagens, a outra é mimética e gravada nos momentos 
de diálogo dos personagens. Como o filme era um curta, a melhor forma foi gravar o roteiro visual inteiro, com pausas propositais, e depois editar e mixar o áudio gravado dentro dos espaços disponiveis no áudio original do filme. Tudo foi feito em uma manhā, o que é bastante para um filme de apenas oito minutos. No caso de um longa-metragem, esse processo não poderia ser aplicado, mas algo semelhante à dublagem, com o auxílio de um time code.

Finalmente, fizemos vârias cópias em DVD e arquivo jpeg1.

\subsection{O questionário}

O passo seguinte foi a elaboração de um questionário de compreensão do filme, o qual seria aplicado a dois grupos de espectadores deficientes visuais: um que assistiria ao filme sem audiodescriçāo, e outro que assistiria com audiodescrição. $O$ questionärio continha as seguintes perguntas:

1. Quem é o personagem principal? Qual seu nome?

2. Quern é Isabel? Qual sua relação com Jorge?

3. Quais sảo seus planos para o domingo?

4. Jorge faz o que Isabel quer?

5. O que ele faz para se livrar de Isabel? Como ele sai de casa?

6. O que acontece com Jorge durante o jogo?

7. Qual time gannha o jogo? Por quê?

8. Por que Jorge vai à casa de Antônio depois do jogo?

9. O que acontece na casa de Antonio?

10. Quem é o homem que conversa com Jorge no final do filme?

11. Por que ouvimos aquele tipo de música na cena final? (para o público da versão sem audiodescrição)

12. Por que seus corpos estāo em azul? (para o público da versāo com audiodescriçāo)

13. Por que Isabel chora quando ela encontra a camisa de Jorge? (para público da versāo com audiodescriçāo)

14. O que acontece com Jorge no final do filme? 
Obviamente que, para o público que assistiu ao filme apenas em sua versào original, não podiamos fazer qualquer pergunta referente às imagens.

\section{Resultados do teste de compreensão sem e com a audiodescrição}

O primeiro grupo, aquele que assistiu apenas à versão original sem audiodescrição, a porcentagem de respostas certas foi de $40 \%$. Um fato interessante foi ouvir as interpretaçōes ou "adivinhaçōes" que os participantes fizeram sobre o filme. Por exemplo, muitos imaginaram que Jorge estava saindo de uma estação de trem; ou na cena de sexo, em que os sussurros e gemidos de Isabel foram interpretados por alguns como dor e agonia.

No grupo que assistiu ao filme com audiodescriçāo, o nivel de acertos foi de $95 \%$, com exceçăo de pcquenos detalhes que nāo ficaram muito claros, como por exemplo, para onde Jorge vai após o jogo de futebol, se vai para a casa dele ou para a casa de Antonio, onde flagra Isabel na cama com o amigo. Nada realmente significativo para o entendimento do filme.

Um dos comentários sobre a versāo audiodescrita feito por um dos participantes foi: "Eu estou acostumado a ouvir filmes sem audiodescrição. A audiodescrição é muito importante porque evita que fiquemos imaginando muito, que nos sintamos ansiosos sobre o que está acontecendo (...) Assim, a audiodescriçāo nos estimula, nos faz sentir vontade de assistir mais filmes".

\section{Conclusões preliminares}

Nesta breve investigação, pudemos identificar três perfis distintos, que dão uma idéia geral sobre a situação dos cidadãos cegos e deficientes visuais em relação ao acesso ao meio audiovisual na capital mais importante do nordeste do Brasil, e aquela com o maior número de cegos e deficientes visuais da região.

Apesar de óbvia, a conclusão de que a audiodescrição possibilita a compreensāo total do enredo de um filme ou programa 
tem de ser reforçada de forma cumulativa. Como vimos neste artigo, não só os leigos no assunto estāo munidos de argumentos e suposições erróneas sobre um direito inquestionável do cidadão portador de deficiência visual, mas também as pessoas que atuam junto a esses cidadāos.

Outra conclusāo óbvia, mas importante de ser reforçada, è o fato de que nenhum acesso real e efetivo é dado a esses cidadāos à televisāo aberta e/ou paga no Brasil, muito menos ao cinema. Num pais em desenvolvimento como o nosso, a questão da acessibilidade parece ainda não ter importāncia, mesmo que apoiada por leis que obriguem a sua implantação. Os direitos sociais sāo ofuscados por demandas econômicas e políticas, e a audiodescrição permanece como uma atividade ainda por ser descoberta no pais, bem como o mercado promissor que a espera.

Contudo, iniciativas isoladas, como a do grupo de pesquisa em questão, começam a surtir algum efeito. A pesquisa em audiodescriçāo já teve seu espaço garantido na Televisāo Educativa da Bahia em julho de 2006. O contato com instituiçōes do Rio e Sāo Paulo, onde o teste de recepçāo será aplicado em breve, tem servido também para conscientizar os próprios cegos e deficientes visuais de que há recursos disponiveis para que seu acesso ao meio audiovisual seja efetivado.

Talvez o mais importante fator desta simples pesquisa tenha sido contradizer um dos dois principais argumentos das associaçōes de radiodifusão que participaram da consulta pública sobre acessibilidade audiovisual, e que se mostraram contrárias à implantaçäo da audiodescrição. $O$ argumento de que não dispomos de recursos tecnológicos para implantar a audiodescrição na televisāo brasileira. Com ele, o argumento de que rios de dinheiro terāo de ser gastos com a televisão analógica também nảo confere. A tecla SAP, já disponível na televisāo brasileira, e estúdios de dublagem seriam suficientes para ativar a audiodescriçāo no Brasil e garantir o acesso de milhōes de cidadāos brasileiros ao meio audiovisual. Basta um pouco de vontade e imaginação. 


\section{Referências bibliográficas}

ABNT. (2005) Acessibilidade cm comunicaçào na televisāo, NBR 15290, 10 páginas. Disponivel no site www.abnt.org.br.

FRANCO, E.P.C. \& SANTIAGO ARAÜJO, V.L. (2003) Reading Television: Chccking Deaf People's Reactions to Closed Subtitling in Fortaleza, Brazil, in GAMBIER, Yves (ed.) Screen Translation (Special issue of The Translaton, vol.9, no.2, Manchester: St. Jerome, p. 249-267.

FRANCO, E. P. C. (2006) Legenda e áudio-descriçāo na televisão garantem acessibilidade a deficientes, Revista Ciência e Cutlura, jan./ mar, vol.58, no.1, Sāo Paulo: Unicamp, p. 12-13.

NEVES, Joselia. (2005) Audiovisual Translation: Subtitling for the Deaf and Hard-of-Hearing. Tese de doutoramento nāo-publicada, Roehampton University, University of Surrey.

15/08/2004, Visāo, em Revista O Globo, p. 11. 
